\title{
Analyzing the Effect of Radiation on Human beings of Electromagnetic waves from BTS and MS in Kushtia, Bangladesh
}

\author{
Md. Shariful Islam ${ }^{\mathrm{a} *}$, Md.Ashek Raihan Mahmud ${ }^{\mathrm{b}}$, Md. Sadek Ali ${ }^{\mathrm{c}}$, Md Jashim Uddin ${ }^{\mathrm{d}}$ \\ a,b,c,d Department of Information and Communication Technology, Islamic University, Kushtia, Bangladesh \\ E-mail: aafmsi1976@gmail.com, ${ }^{b}$ ashekraihan.iubd@gmail.com, ${ }^{c}$ sadek@ice.iu.ac.bd, ${ }^{\mathrm{d}}$ jashim@iu.ac.bd
}

Article History: Received: 10 January 2021; Revised: 12 February 2021; Accepted: 27 March 2021;

Published online: 28 April 2021

\begin{abstract}
Based on Base Transceiver Station (BTS) and Mobile Station (MS) radiation, the residence of Kushtia district in Bangladesh is usually concerned with the potential health effects. Inhabitants, living in this part of Bangladesh are using communication, internet browsing, and other related uses with the help of mobile cellular communication system. The subscriber needed improving radio coverage, excellent communication networks, and quicker speed for internet browsing with the recent developments in mobile cellular communication technologies. To meet this demand, service providers of mobile cellular companies set up several BTS, which emit harmful radiation that has extremely detrimental impact on the human body. Through this paper, the effects of electromagnetic radiation of MS as well as BTS on the human body have been analyzed and Electromagnetic Field (EMF) radiation levels of MSs along with BTSs located in this region have been measured. These measurements have been compared with the measured value provided by the World Health Organization (WHO) and International Commission of Non-Ionizing Radiation Protection (ICNIRP). Finally, a cross-sectional analysis was carried out to evaluate the understanding and self-reported health risks of Electromagnetic waves (EMW) radiation emitted from the MS as well as BTS among the inhabitants of this region who are living near and a little away from BTS.
\end{abstract}

Keywords: Mobile Cellular Communications, Base Transceiver Station (BTS), Mobile Station (MS), Electromagnetic field (EMF), Ionizing and Non-Ionizing Radiation

\section{Introduction}

The present era is the technological era. The inhabitants of the world are presently dependent on technology. The use of mobile phones called Mobile Station (MS) has been increasing rapidly in the world for the last few decades and in the coming days, the same pattern will continue as the worldwide number of cell phone subscribers are continuously rising and applications are increasingly data-intensive (Nokia, "Looking ahead to 5G", Espoo, Finland, 2014, Cisco, 2015, Ericsson, 2014, GSMA Intelligence, 2019). According to S.O'Dea's statistics, the number of mobile users in the world in 2020 was 6.95 billion. Based on this figure, they also predict that the number of mobile users in 2021 and 2024 will stand at 7.1 billion and 7.41 billion respectively. Although Bangladesh is a developing country, the numbers of mobile users are increasing in line with the world. As stated by Bangladesh Telecommunication Regulatory Commission (BTRC) statistics, at the end of December 2020, in Bangladesh, the number of active mobile users was 170.137 million (Bangladesh Telecommunication Regulatory Commission, 2020). With the increase in the number of mobile users, it has become necessary to escalate the number of Base Transceiver Station (BTS) is called Mobile Tower of cell phone companies. BTSs are nothing but radio transmitters positioned on either free-standing masts or on buildings that allow the mobile user and a network to communicate wirelessly. BTS antennas operate macrocells or macrosites covering an area of approximately 9.67 kilometers in diameters using a high power transceiver typically tens of watts placed on a standalone tower usually 32.8 to 98.4 foot high from the ground or on the top of the buildings or connected to the side of buildings. Usually, every tower supports $120^{\circ}$ sectoring three antennas to cover $360^{\circ}$ or one omnidirectional antenna. Two types of radiation patterns are formed from antennas, the horizontal plane where radiation is maximum in front and reduces in the other direction; another is vertical plane where radiation is maximum in main lobe and less in minor lobe. The main lobe of the radio antenna is slightly lower; however, it does not reach the ground level until crosses at least 185-foot from the tower. Radio signals are transformed to the antennas via cables and then propelled into the region or cell around the BTS as radio waves (G. Neubauer, H. Haider, K. Lameds et al.2003). People who are living within 164foot to 985 -foot radius from the BTS antennas are in the high electromagnetic radiation zone at extreme health risk (Mobile Telecommunications and Health Research Program (MTHR), Report-2007). According to the International Radio Frequency (RF) region, Kushtia district is also located of the region. The district is home to the tomb of the emperor Lalanshah, Rabindranath's Kuthibari, many wise people including Mir Mosharraf Hossain, the author of Bishad-Sindu. The only government Islamic University established after the independence of the country is located in this district. It is called the cultural capital of Bangladesh. The area of this district is $1621.15 \mathrm{sq} . \mathrm{Km}$. It has a population of $23,66,811$ of which $50.6 \%$ are males and $49.14 \%$ are females. $95.72 \%$ of the population is Muslim, $4.22 \%$ is Hindu and $0.08 \%$ follows other religions. The numbers of mobile cell phone users are increasing in the Kushtia district. 
Therefore, mobile companies are also increasing the number of BTS to cover the cellular services with a satisfactory level among the people of the region. The wireless communication between BTS and MS has a lot of radiation effects on human health (World Health Organization, Electromagnetic Fields and Public Health, 2014, M. Otto and K. E. von Muhlendahl, 2007, A. W. Preece, S. Goodfellow, M. G. Wright et al, 2005, M. Blettner, B. Schlehofer, J. Breckenkamp et al., 2009, A. P. M. Zwamborn, S. H. J. Vossen, et al., 2003, P. Elliott, M. B. Toledano, J. Bennett et al., 2010, Tapasy Rabeya, Mst. Eshita Khatun, Syed Akhter Hossain, 2020, Sheikh Mohammed Shariful Islam, 2014, Ahmed Mahfuz Tamim, Mohammad Rashed Iqbal Faruque, Mayeen Uddin Khandaker et al., 2020).

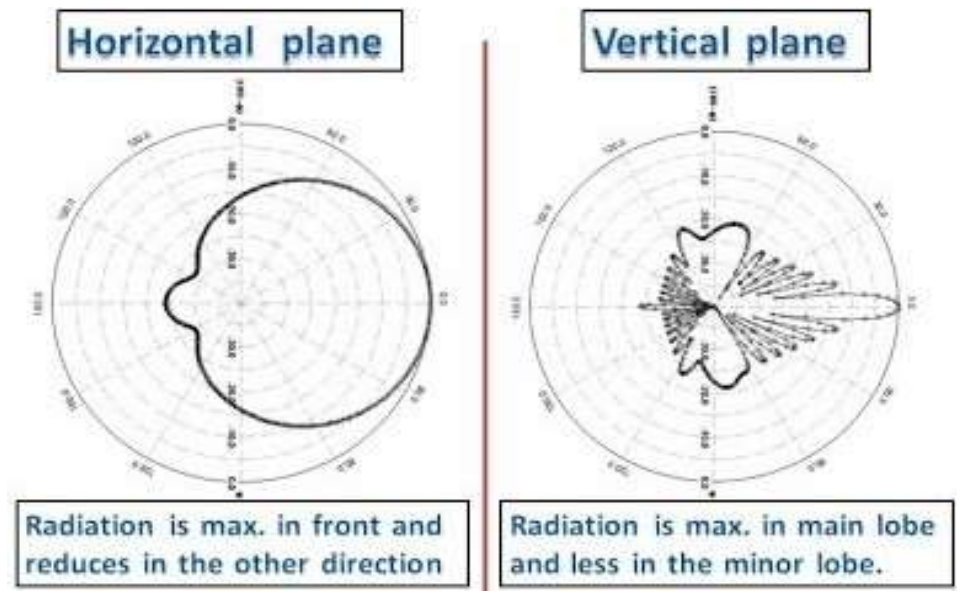

Fig. 1 Radiation pattern of an antenna (Prof. Girish Kumar, 2010)

As far as I know, no literature has been published on the harmful effects of radiation from MS as well as BTS on the people in the Kushtia district in Bangladesh. The main purpose of this study is to identify the harmful effects of radiation on the human body emitted from BTS and MS to raise awareness of the aforementioned effect among the people of this region. To implement the purpose of this work, Firstly, the effects of electromagnetic radiation of MS as well as BTS on the human body have been analyzed and EMF radiation levels of BTSs located in this region have been measured. Secondly, these measurements have been compared with the measured value provided by the World Health Organization (WHO) and International Commission of Non-Ionizing Radiation Protection (ICNIRP). Finally, a crosssectional analysis was carried out to evaluate the understanding and self-reported health risks of EMW radiation emitted from the MS as well as BTS among the inhabitants of this region who are living near and a little away from BTS. The major contribution of this paper can be summarized as follows:

1. The effects of Electromagnetic Radiation of MS as well as BTS on the human body (five organs tissues) have been analyzed and Electromagnetic field (EMF) radiation levels of MSs along with BTSs located in study region have been measured.

2. These measurements have been compared with the measured value provided by the WHO and ICNIRP.

3. Finally, a cross-sectional analysis was carried out to evaluate the understanding and self-reported health risks of EMW radiation emitted from the MS as well as BTS among the inhabitants of this region who are living near and a little away from BTS. The remains of the paper are structured as follows: In part II, cellular communication situation of Kushtia district perspective in Bangladesh. In part III, analyzing different parameters for measuring radiation. In part IV, observational tests. In part V results and discussion. Conclusion is shown to the last part of this paper.

\section{Cellular Communication Situation of Kushtia District Perspective in Bangladesh}

At present, the number of MS users in Bangladesh is 170.137 million and the number of BTS or mobile phone towers is about 3550 which is being served by five major mobile phone operators, namely; Banglalink, Grameenphone, Robi, Airtel, and Teletalk (The daily Star,"HC seeks BTRC report on mobile tower radiation, 2019). According to the above statistics, the total number of mobile towers and mobile users are approximately 100 and 2.6 million, respectively in Kushtia, Bangladesh. Cell phone towers called BTS are being set up in densely populated areas to meet the growing demand for mobile cellular communications and to improve network coverage. As a result, the residents of the area are suffering from various diseases/health threats that have been mentioned. Mobile cell tower antennas in the Kushtia district of Bangladesh are producing based on three frequency ranges, namely: $900 \mathrm{MHz}, 1800 \mathrm{MHz}$, and $2100 \mathrm{MHz}$ respectively, for the supply of up to $4 \mathrm{G}$ networks by various mobile phone operators. People living in the vicinity of these high frequency microwaves emitted from cell phone. 
Table 1. Safety limit values of radiated power density and electric field strength measured by WHO and present situation in Kushtia, Bangladesh for the cellular communication system

\begin{tabular}{lcccc}
\hline $\begin{array}{l}\text { Different } \\
\text { Frequency Bands } \\
(\text { MHz) }\end{array}$ & $\begin{array}{c}\text { WHO } \\
\text { recommended } \\
\text { standard power } \\
\text { level density } \\
\left(\mathbf{w} / \mathbf{m}^{\mathbf{2}}\right)\end{array}$ & $\begin{array}{c}\text { Measured power level } \\
\text { density by BTRC in } \\
\text { Kushtia, Bangladesh } \\
\left(\mathbf{w} / \mathbf{m}^{2}\right)\end{array}$ & $\begin{array}{c}\text { WHO } \\
\text { recommended } \\
\text { standard level of } \\
\text { Electric field }(\mathbf{v} / \mathbf{m})\end{array}$ & $\begin{array}{c}\text { Measured Electric } \\
\text { field by BTRC in } \\
\text { Kushtia, Bangladesh } \\
(\mathbf{v} / \mathbf{m})\end{array}$ \\
\hline GSM 900 & 4.66 & 10.37 & 41.99 & 52 \\
GSM 1800 & 9.01 & 10.38 & 57.99 & 71.56 \\
GSM 2100 & 10.02 & 5.56 & 61.01 & 66 \\
(UMTS) & & & & \\
\hline
\end{tabular}

towers may be at risk of various health problems (S. Reza, 2019). Due to the risk of cell phone tower radiation, owners of multi-storied buildings in Kushtia, Bangladesh, sometimes have trouble renting apartment around the top of the roof. However, some residents of this region having still lack of awareness of this issue. In March 2017, a high-level committee formed by the Ministry of Health of Bangladesh submitted a report to the High Court regarding the radiation of BTS on which mobile operators were not following the WHO guidelines to provide cellular mobile communication between BTS and MS. Some of the indicators are considered for radiation measurement to include the level of power density, the strength of electric field and SAR rate. A report has mentioned by WHO, how much power density level and electric field strength is safe for human of different frequency bands in cellular communication systems. The BTRC has measured radiated power density and electric field strength from cell phone towers (BTSs) in Kushtia district including Dhaka which is the capital city in Bangladesh and a comparison is shown in Table 1 with the standard of measurement for safety limits given by WHO. Since Bangladesh is a densely populated country, many rural areas of Kushtia district including Kushtia town is also densely populated area. Therefore, BTRC should monitor the amount of radiation emitted from mobile cell phone towers which the tribunal has recommended (Dhaka Tribune, 2019). Usually, two types of radiations are formed, namely: Ionizing and Non-ionizing radiations. The work we are analyzing in this paper is non-ionizing radiation. There are many sources of EMF, like Cell phone towers and MSs. The amount of power transmission from cell phone tower, as well as MS, is $20 \mathrm{~W}$ and 1 to $2 \mathrm{~W}$, respectively. Two types of antennas (Rectangular, Circular) are used in cell phone towers at Base Stations in Kushtia, Bangladesh.

\section{Analyzing Different Parameters for Measuring Radiation}

Radiation is measured depending on two parameters, pattern of radiation and density of the power of the transmitted frequency from the base station of the cell phone towers antennas. The radiation pattern is shown in Fig.2. The radio frequency safety limit depends on two parameters, namely whether the power density level is greater than the strength of the electric and magnetic fields. In the case of safety limits, the electric and magnetic fields of low frequencies are more significant but for the high frequencies only value of power density should be determined. A Radio Frequency (RF) transmitter's far field, relation between density of power level and field strength is shown by the following equation.

$$
\operatorname{Pd}=\frac{E_{\text {efs }}}{377}
$$

Where, $P_{\mathrm{d}}$ is the density of power $\left(\mathrm{Watt} / \mathrm{m}^{2}\right)$ and $\mathrm{E}_{\text {efs }}$ is the electric field strength $(\mathrm{Volt} / \mathrm{m})$ and 377 is the characteristics impedance for free space.

The radiation measurements have been made from the survey areas of BTS and MS. An isotropic broadband antenna (19.99 MHz to $5.99 \mathrm{GHz})$ and a portable spectrum analyzer $(6.44 \mathrm{GHz})$ have been used to measure BTS radiation (Thae Mar Than, Su Su Yi Mon, 2020). On the Other hand, a power density meter (Electrosmog meter, ModelCORNET®ED-78SPlus) has been used to measure the radiation of MS. With the help of these instruments, field strength of Electromagnetic waves, level of power density and magnetic field of low frequency have been measured in the human habitable environments (Electrosmog Meter, Model NO. CORNET®ED-78SPlus, 2019). The device has a high sensitivity of $100 \mathrm{MHz}$ to $8 \mathrm{GHz}$ RF bandwidth and a sensitivity of 0.1 to $60^{\mu \mathrm{T}}$ (1-600 mG) with a Low Frequency (LF) bandwidth of $50 \mathrm{~Hz}$ to $10 \mathrm{KHz}$ (M. Quamruzzaman, M. Haque, S. Haque, and Utpal Chandra Das, 2020). Three parameters are important to find out how much radiation is absorbed in the human body, namely: Electric field strength, Power density, and Specific Absorption Rate (SAR). To measure the amount of radiation from the RF, absorbed by the human body, SAR is used. A standard value of SAR provided by WHO is $1.66^{\mathrm{w} / \mathrm{kg}}$. The effect of radiation on the five organ tissues of the human body (blood, brain, kidney, muscle, and skin) has been calculated by calculating the value of SAR. With the help of an antenna, Model: N6850A, its effect on the $900 \mathrm{MHz}$ and $1800 \mathrm{MHz}$ frequency bands have been analyzed. This model can provide $1 \mathrm{KW}$ power and $690 \mathrm{MHz}$ to the $2 \times 2690 \mathrm{MHz}$ frequency range. SAR can be calculated by the following equation (Hoque, A. K. M. F., Md. Sazzad Hossain, A. Sattar Mollah, Md. Akramuzzaman, 2013). 


$$
\mathrm{SAR}=\frac{\sigma_{\mathrm{tc}}\left|\mathrm{E}_{\mathrm{efs}}\right|^{2}}{2 \rho_{\mathrm{hmd}}}
$$

Where, $\sigma_{\text {tc }}$ is the tissue conductivity $(\mathrm{S} / \mathrm{m}), \rho_{\mathrm{hmd}}$ is the human mass density $\left(\mathrm{kg} / \mathrm{m}^{3}\right), \mathrm{E}_{\text {efs }}$ is the electric field strength $(\mathrm{V} / \mathrm{m})$. Electric field strength can be calculated by using the following equation.

$$
E_{\text {efs }}=\frac{\sqrt{\left(30 P_{t} G_{t}\right)}}{R}
$$

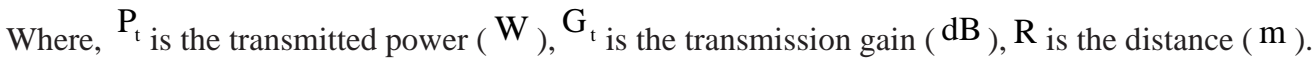

Finally, a cross-sectional survey has been completed among 500 participants in the Kushtia district from September, 2020 to January, 2021. Participants from the study area were selected to get the answer to some questions that became very effective in analyzing the main goal of this work. Participants were selected who are residing near BTS as well as away from BTS. Many of the participants refused to give the answer of some questions due to their busy schedules but about $95 \%$ of the participants were participated spontaneously to give the answer of the questions. Different features were considered of the participants. For example: the use of mobile cell phone, which company's cell phones, at what time and for how long mobile cell phone usage, habits, age, etc are called epidemiological data.

\section{Observational Tests}

Frequency bands of Global System for Mobile Communications (GSM) for radiation measurement of cell phone towers (BTS) which is used in the Kushtia district of Bangladesh. Table-2 shows the frequency bands of GSM. The observational test of Kushtia region shows the measurement data at $950 \mathrm{MHz}$ and $1810 \mathrm{MHz}$ in Table-3.

Table 2. Frequency bands of GSM

\begin{tabular}{lcc}
\hline Frequency bands of GSM & E-GSM & DCS-1800 \\
\hline Frequency, ${ }^{f}$ (MHz) & 900 & 1800 \\
Uplink ${ }^{f}$ (MHz) (MS to BTS) & $880-915$ & $1710.2-1784.8$ \\
Downlink ${ }^{\text {(MHz) (BTS to MS) }}$ & $935-960$ & $1805.2-1879.8$ \\
Numbers of Channel & $1-124$ & $512-883$ \\
Equivalent band of LTE & 8 (Subsets) & 3 \\
\hline
\end{tabular}

Table 3. Extended-GSM 900 and Digital Communication System (DCS)-1800

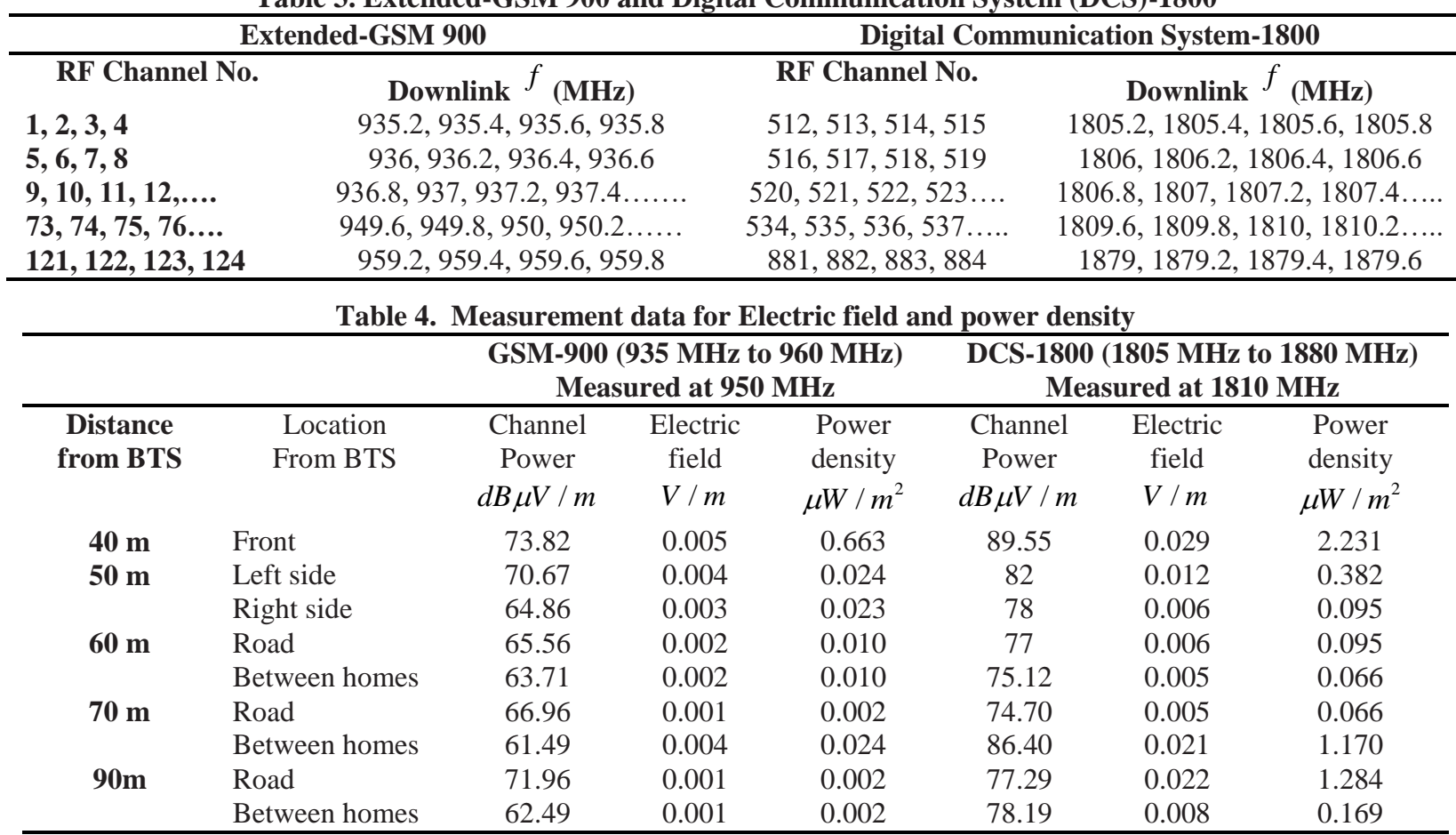


Table 5. Density and conductivity of human tissues

\begin{tabular}{lccc}
\hline Different organ tissue & Density & $\rho_{h m d}\left(\mathrm{~kg} / \mathrm{m}^{3}\right)$ & \multicolumn{2}{c}{ Tissue conductivity $\sigma_{t c}(\mathrm{~S} / \mathrm{m})$} \\
\cline { 3 - 4 } Blood & & For $900 \mathrm{MHz}$ & For $1800 \mathrm{MHz}$ \\
Brain & 1055 & 1.53 & 1.99 \\
Kidney & 1028 & 1.27 & 1.69 \\
Muscle & 1026 & 1.38 & 1.93 \\
Skin & 1028 & 0.93 & 1.33 \\
\hline
\end{tabular}

Data has been recorded by maintaining some distances around the BTS from the BTSs in Kushtia town as well as outside from the town. Measurement data for power density and electric field are shown in Table-4 at GSM $900 \mathrm{MHz}$ and GSM $1810 \mathrm{MHz}$ frequencies. Analytical analysis of electric field and power density depends primarily on the place of the measurement in all areas. Table-5 shows the density and conductivity of five types of human tissues at $900 \mathrm{MHz}$ and $1800 \mathrm{MHz}$ frequency bands.

\section{Results and Discussion}

Channel power $\left(\mathrm{dB} \mu \mathrm{V} / \mathrm{m} / 200 \mathrm{KHz}\right.$ ), power density $\left(\mu \mathrm{W} / \mathrm{m}^{2}\right)$, and electric field $(\mathrm{V} / \mathrm{m})$ at different distances $(40 \mathrm{~m}, 50 \mathrm{~m}, 60 \mathrm{~m}, 70 \mathrm{~m}, 90 \mathrm{~m})$ from the BTS in the survey area were measured using the frequency bands of $950 \mathrm{MHz}$ and $1610 \mathrm{MHz}$ as shown in Table-3. From the measured data, it appears that the magnitude of the channel power and electric field gradually decreased while the measurement location was taken away from the BTS. It is also noticed that different values of channel power, power density, and electric field were found within the same distance. Since there were no obstacles between BTS antennas and some measured location antennas. On the contrary, there were many obstacles between the RF propagation path, such as, buildings, trees or any other reflector of RF signal. Analyzing this measured data, it can be said that people who living near BTS are more exposed to electromagnetic radiation. In the case of $900 \mathrm{MHz}$ and $1800 \mathrm{MHz}$ frequency bands, simulation results of the SAR for different human tissues (blood, brain, kidney, muscle, and skin) are shown in Fig 2, Fig 3, Fig 4, Fig 5, and Fig 6. WHO recommended that a standard value of SAR is $1.66^{\mathrm{w} / \mathrm{kg}}$. From the simulation results it can be seen that antennas need to be set up at slightly greater distances for skin tissues and fewer distances for blood tissues from the BTS for $900 \mathrm{MHz}$, and $1800 \mathrm{MHz}$ frequency bands to get safety limit of SAR. Standard values of SAR were found for the $900 \mathrm{MHz}$, and $1800 \mathrm{MHz}$ frequency bands (16.06 m for blood, $19.15 \mathrm{~m}$ for brain, $17.29 \mathrm{~m}$ for kidney, $25.93 \mathrm{~m}$ for muscle and, $30 \mathrm{~m}$ for skin) and (18.33 m for blood, $21.65 \mathrm{~m}$ for brain, $18.68 \mathrm{~m}$ for kidney, $26.21 \mathrm{~m}$ for muscle, and $32.12 \mathrm{~m}$ for skin) respectively.

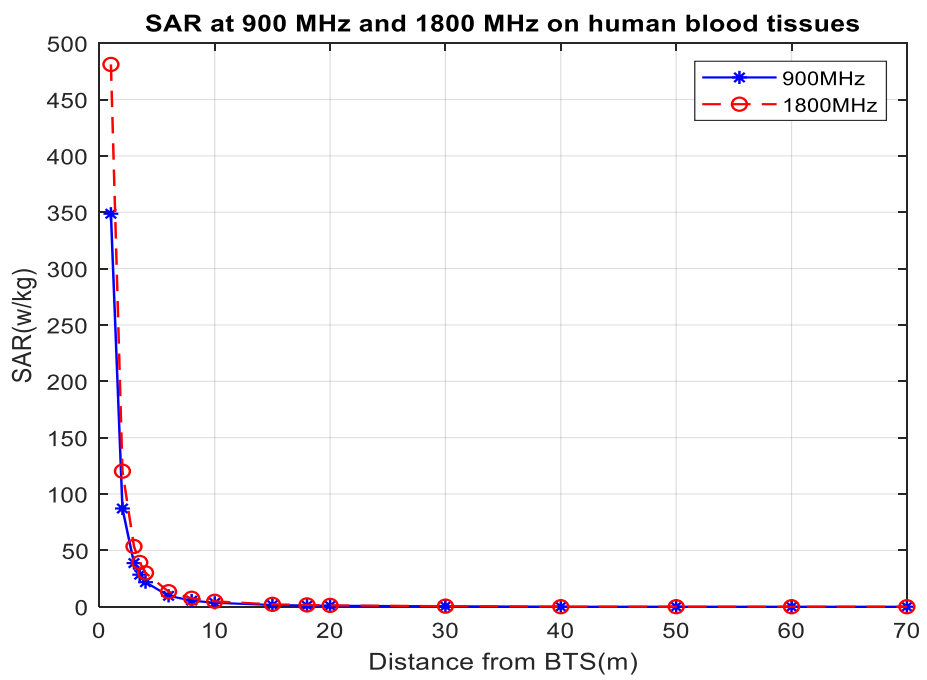

Fig. 2 SAR at $900 \mathrm{MHz}$ and $1800 \mathrm{MHz}$ on human blood tissues 


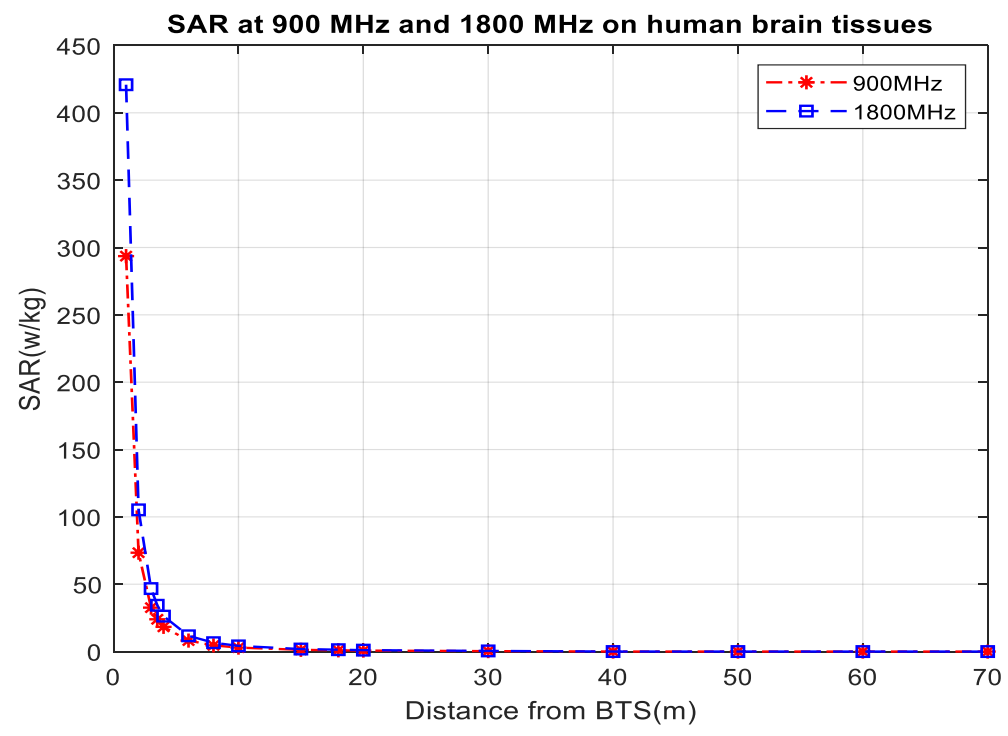

Fig.3 SAR at $900 \mathrm{MHz}$ and $1800 \mathrm{MHz}$ on human brain tissues

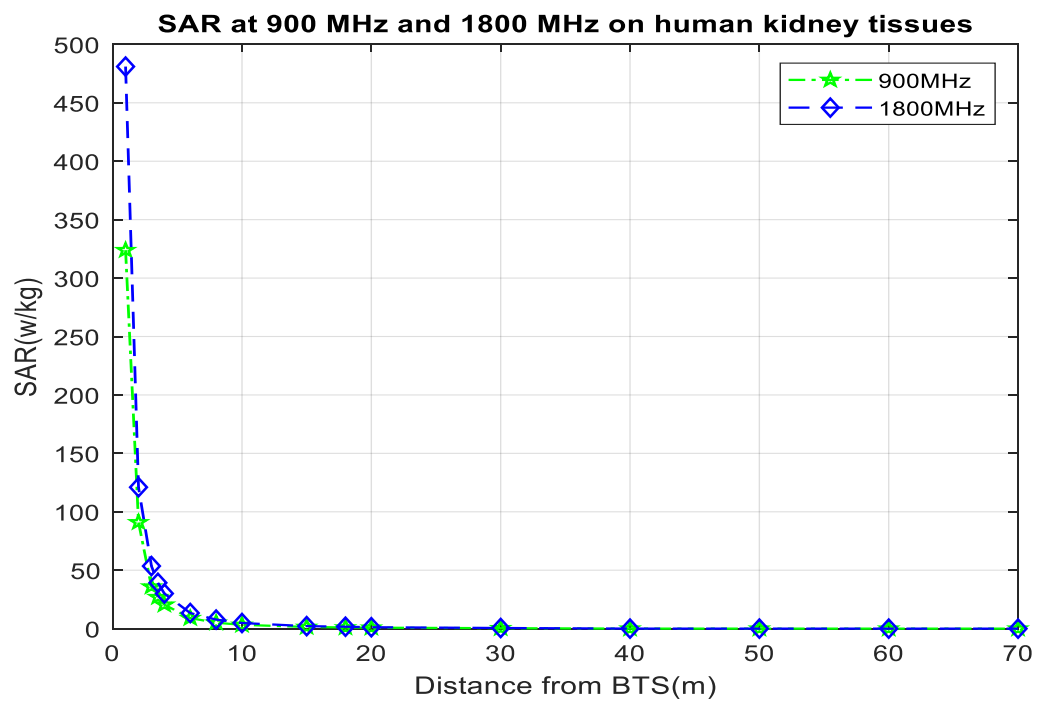

Fig.4 SAR at $900 \mathrm{MHz}$ and $1800 \mathrm{MHz}$ on human kidney tissues

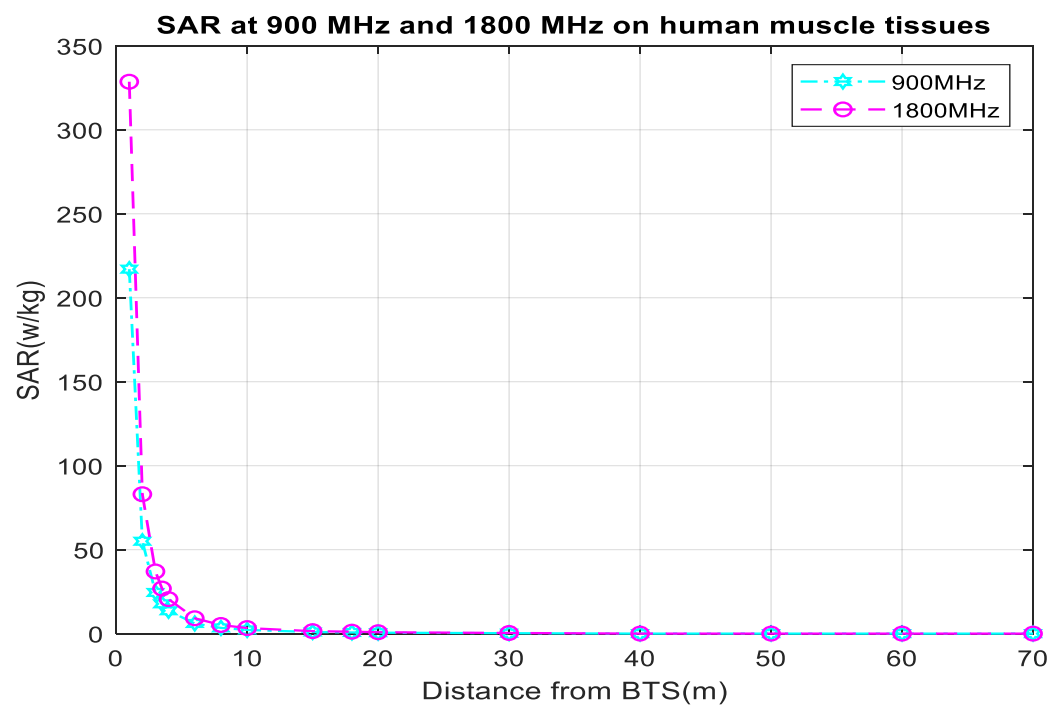

Fig. 5 SAR at $900 \mathrm{MHz}$ and $1800 \mathrm{MHz}$ on human muscle tissues 


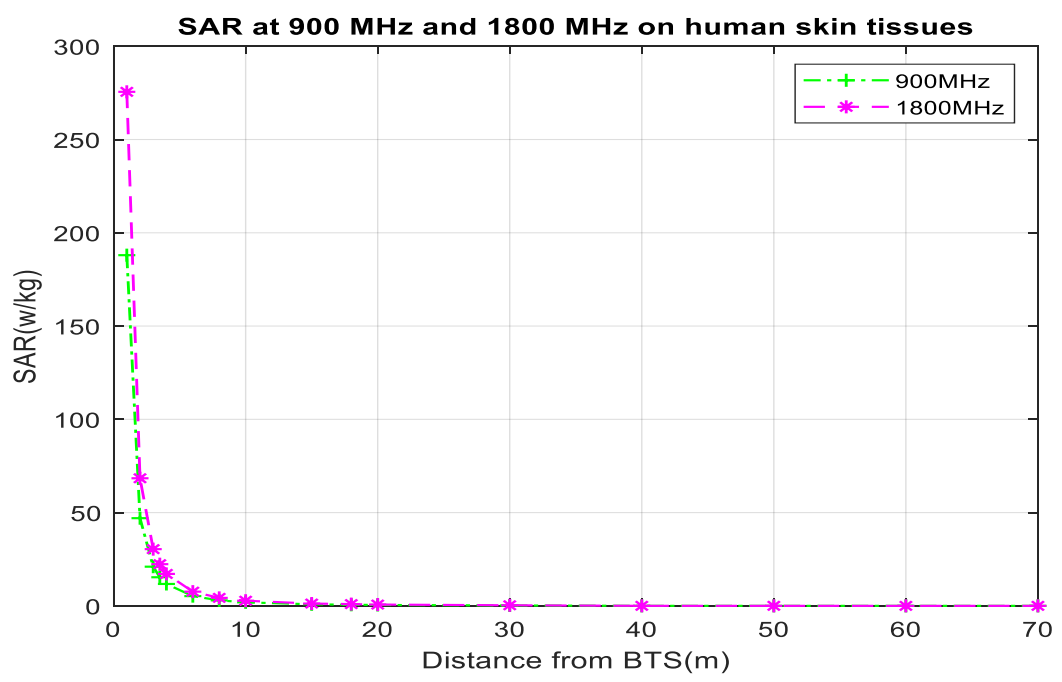

Fig. 6 SAR at $900 \mathrm{MHZ}$ and $1800 \mathrm{MHz}$ on human skin tissues

The amount of radiated power from the MSs is measured $\left(\mathrm{mW} / \mathrm{cm}^{2}\right)$ in each MS based on different situations, namely; usual data, with cellular mobile data, including WiFi data and along the signal are shown in Fig. 7, Fig. 8, Fig. 9, and Fig. 10. Analyzing the data of Fig. 7, it can be said that when radiated power from MSs $\left(0.09-0.98 \mathrm{~mW} / \mathrm{cm}^{2}\right)$ in terms of usual data (MS is ON but no signal) is measured the highest number of MSs to be $44 \%$ and, radiated power $\left(29-38 \mathrm{~mW} / \mathrm{cm}^{2}, 39-48 \mathrm{~mW} / \mathrm{cm}^{2}, 49-58 \mathrm{~mW} / \mathrm{cm}^{2}\right.$ and, $\left.59-68 \mathrm{~mW} / \mathrm{cm}^{2}\right)$ are measured the lowest number of MSs to be $1 \%$.

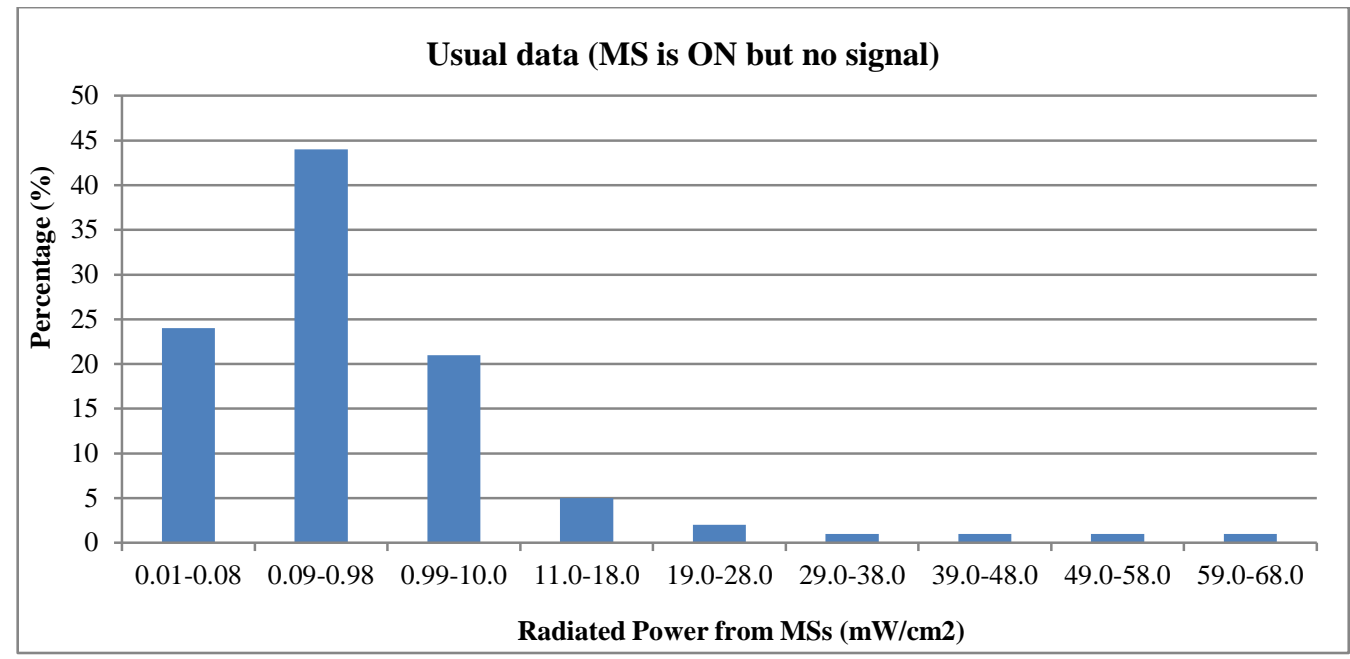

Fig. 7 Usual data (MS is ON but no signal)

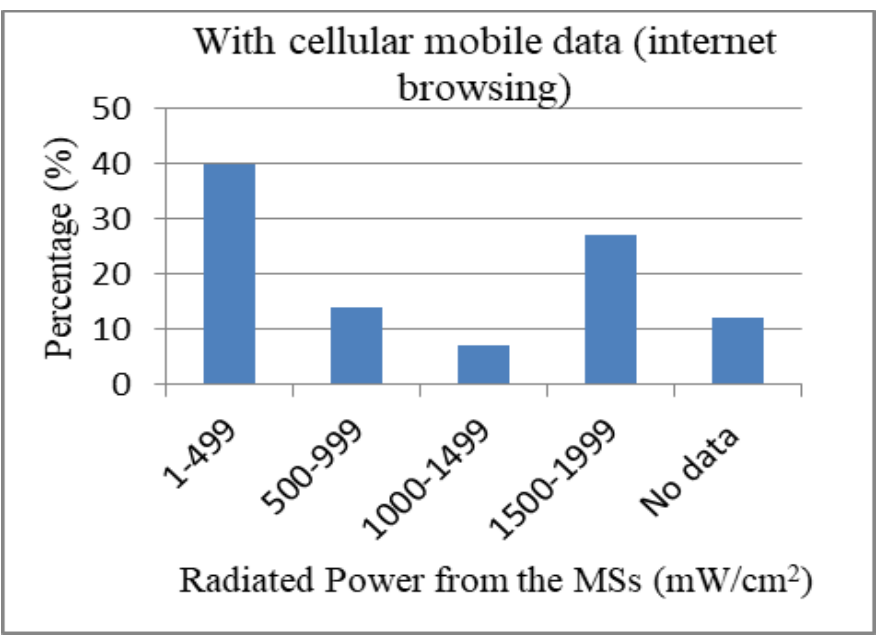

Fig.8 With cellular mobile data (internet browsing) 
In the case of cellular mobile data (internet browsing), $1-499 \mathrm{~mW} / \mathrm{cm}^{2}$ is $40 \%, 500-999 \mathrm{~mW} / \mathrm{cm}^{2}$ is $14 \%, 1000-1499$ $\mathrm{mW} / \mathrm{cm}^{2}$ is $7 \%, 1500-1999 \mathrm{~mW} / \mathrm{cm}^{2}$ is $27 \%$, and no data from $12 \%$ MSs was available as shown in Fig. 8. In the survey area, along signal (talking time) $1-499 \mathrm{~mW} / \mathrm{cm}^{2}$ radiated power is found in $37 \%$ of $\mathrm{MSs}, 500-999 \mathrm{~mW} / \mathrm{cm}^{2}$ radiated power is $4 \%, 1000-1499 \mathrm{~mW} / \mathrm{cm}^{2}$ radiated power is $12 \%, 1500-1999 \mathrm{~mW} / \mathrm{cm}^{2}$ radiated power is $42 \%$. No radiated power was found from 5\% MSs as shown in Fig. 10.

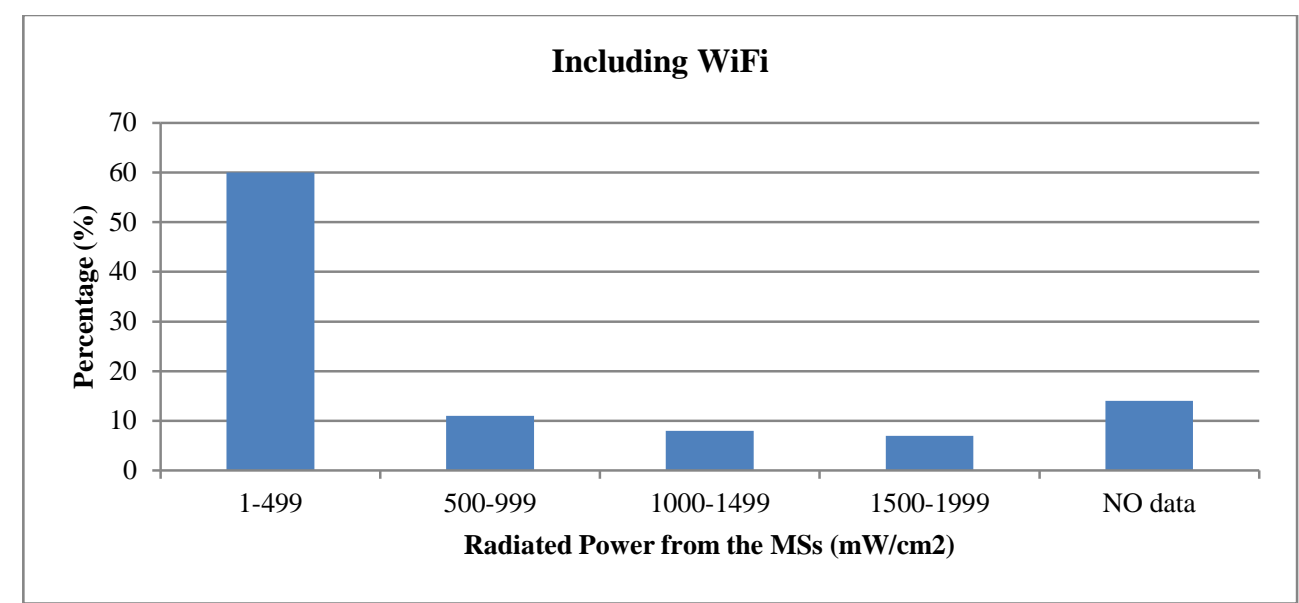

Fig. 9 MSs data including WiFi

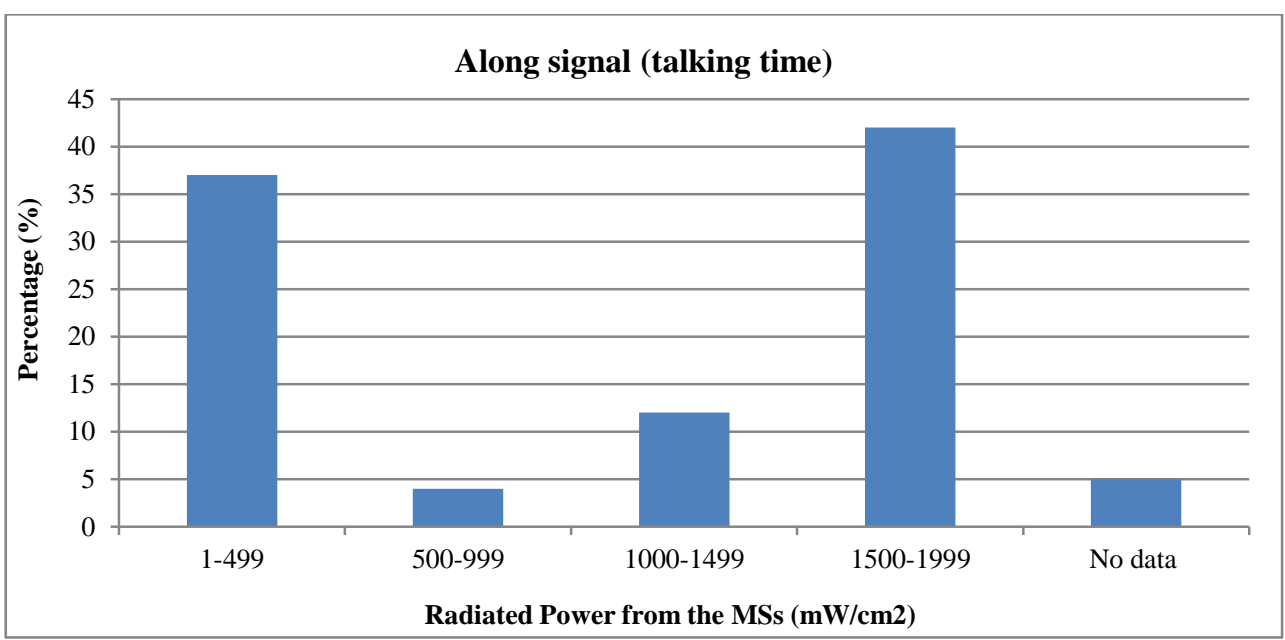

Fig. 10 Along signal with talking time

The radiated power limit of MS in Bangladesh is $0.465 \mathrm{~mW} / \mathrm{cm}^{2}$ at $950 \mathrm{MHz}$ frequency and $0.925 \mathrm{~mW} / \mathrm{cm}^{2}$ at 1850 $\mathrm{MHz}$ frequency recommended by ICNIRP. Based on the ICNIRP recommended values, most of the measured values are found above the threshold limits except for usual data (MS is ON but no signal) $0.01-0.08 \mathrm{~mW} / \mathrm{cm}^{2}(24 \%)$ and $0.09-0.98$ $\mathrm{mW} / \mathrm{cm}^{2}(44 \%)$. Data were collected (epidemiological data) from the study area on what problems are experiencing of MSs Users; from what age have they been using MS, how many years have they been using MS, how many hours do MS users use MS everyday as shown in Fig. 11, Fig. 12, Fig. 13, and Fig. 14. The physical and mental problems of the human body due to the use of MSs are shown in Fig. 11. 


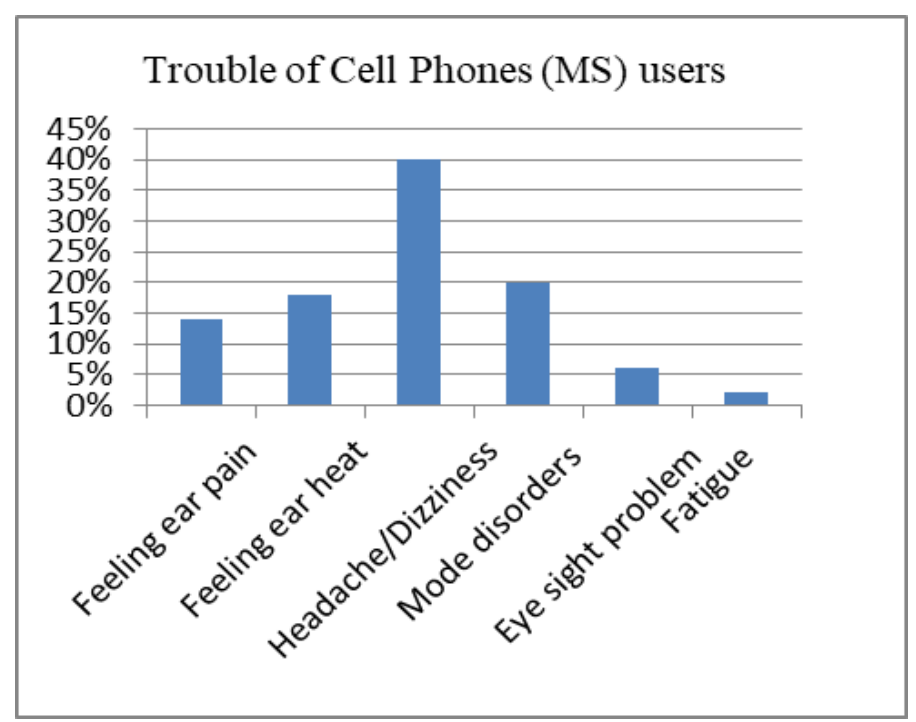

Fig. 11 Trouble of Cell phones users

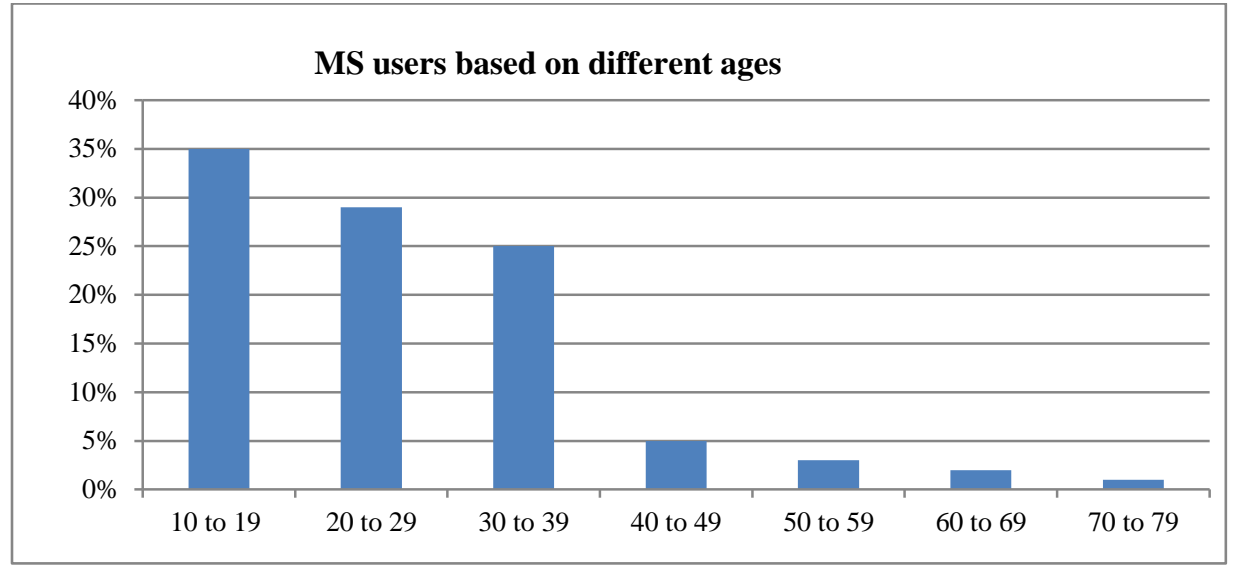

Fig. 12 Cell phones users of different ages

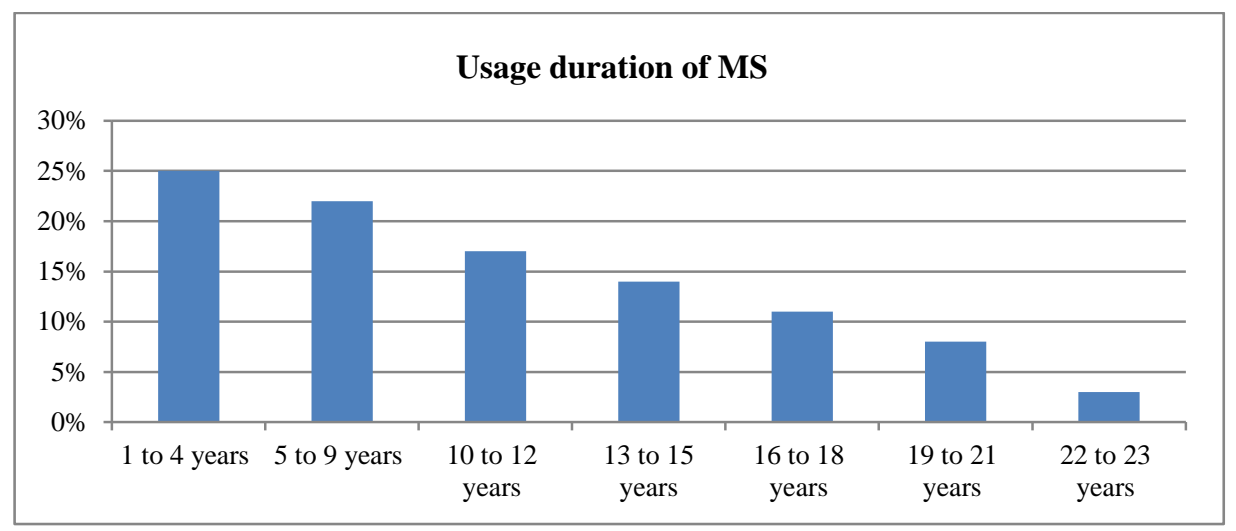

Fig. 13 Usage duration of MS 


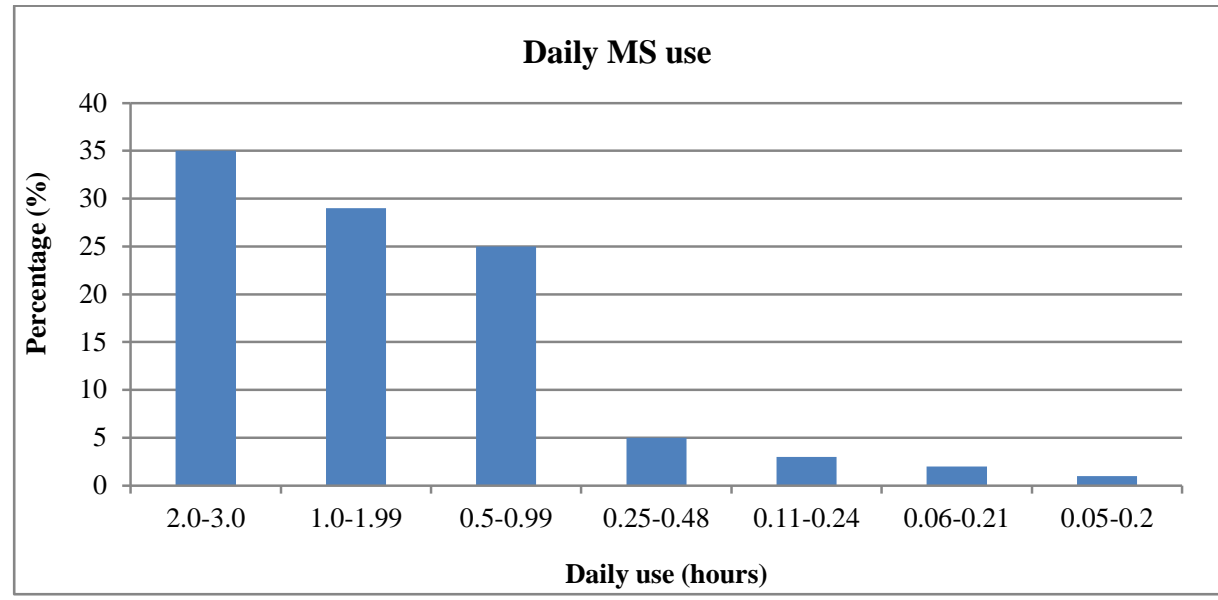

Fig. 14 MS use per day

Fig. 13 shows, how many years MS users have been using MS. Duration of usage in years include 1-4 years (25\%), 5-9 years (22\%), 10-12 years (17\%), 13-15 years (14\%), 16-18 years (11\%), 19-21 years (8\%), and 22-23 years (3\%). Duration of usage per day in hours include 2.0-3.0 hours (35\%), 1.0-1.99 hours (29\%), 0.5-0.99 hours (25\%), 0.25-0.48 hours (5\%), 0.11-0.24 hours (3\%), 0.06-0.21 hours (2\%), and 0.05-0.2 hours (1\%) as shown in Fig. 14.

\section{Conclusion}

In this paper, the effects of electromagnetic radiation of MS as well as BTS on the human body have been analyzed and Electromagnetic Field (EMF) radiation levels of MSs along with BTSs located in this region have been measured. These measurements have been compared with the measured value provided by the World Health Organization (WHO) and International Commission of Non-Ionizing Radiation Protection (ICNIRP). From the analyzed MSs Data, it has been found that in some cases radiated power exceeds the threshold limits which can have a significant impact on the human body. The matter should be reported to the MS users in the study area so that they can take the right approach in MS usage. Finally, a cross-sectional analysis was carried out to evaluate the understanding and self-reported health risks of Electromagnetic waves (EMW) radiation emitted from the MS as well as BTS among the inhabitants of this region who are living near and a little away from BTS. Some mobile cellular communication equipment and verbal data has been used to analysis this work. There may be some errors in the readings of the device and the users may not give proper thoughtful answer during data collection.

\section{Acknowledgement}

This research was supported by the Department of Information and Communication Technology in Islamic University kushtia-7003, Bangladesh under grant No. 2020/634.

\section{References}

1. P. M. Zwamborn, S. H. J. Vossen, B. J. A. Leersum, M. A. Ouwens, and W. N. Makel (2003). "Effects of global communication system radio-frequency fields on well-being and cognitive functions of human subjects with and without subjective complaints," TNO-Report FEL-03-C148.

2. W. Preece, S. Goodfellow, M. G. Wright et al. (2005). "Effect of $902 \mathrm{MHz}$ mobile phone transmission on cognitive function in children," Bioelectromagnetics, vol. 26, no. 7, pp. S138-S143.

2. Ahmed Mahfuz Tamim, Mohammad Rashed Iqbal Faruque, Mayeen Uddin Khandaker et al. (2020). "Electromagnetic radiation reduction using novel metamaterial for cellular applications", Journal of Radiation Physics and Chemistry.

3. Bangladesh Telecommunication Regulatory Commission (2020), http://www.btrc.gov.bd/content/mobile-phonesubscribers-bangladesh-december-2020

4. Cisco, Cisco visual networking index: Global mobile data traffic forecast update, 2014-2019, San Jose, CA, USA, (2015). [Online]. Available: http://www.cisco.com/c /en/us /solutions/collateral/service-provider/ visual networking -index-vni/white_paper_c11-520862.pdf.

5. Dhaka Tribune (2019). "HC asks BTRC for report on mobile tower radiation", http://www.dhakatribune. com/Bangladesh/court/2019/04/25/hc-asks-btrc-for-report-on-mobile-tower-radiation.

6. Electrosmog Meter, Model NO. CORNET®ED-78SPlus (2019). Cornet. Retrieved from http://electrosmog.org/ Last accessed 11 Nov.

7. Ericsson, Ericsson mobility report - on the pulse of the networked society, Stockholm, Sweden, (2014). [Online]. Available: http://www.ericsson.com/ res/docs/2014/ ericsson-mobility-report-November-2014.pdf.

8. G. Neubauer, H. Haider, K. Lameds et al. (2003), "Measurement methods and legal requirements for exposure assessment next to GSM base stations", in Proceedings of the $15^{\text {th }}$ International Zurich Symposium on Electromagnetic Compatibility. 
9. GSMA Intelligence. Definitive data and analysis for the mobile industry (2019). Accessed: 25.3.2019, [Online]. Available: https://www.gsmaintelligence.com/.

10. Hoque, A. K. M. F., Md. Sazzad Hossain, A. Sattar Mollah, Md. Akramuzzaman (2013). "A Study on Specific Absorption Rate (SAR) due to nonionizing radiation from wireless/telecommunication in Bangladesh", Am. J. Phys. Appl. no.1(3), pp.104-110.

11. M. Blettner, B. Schlehofer, J. Breckenkamp et al. (2009). "Mobile phone base stations and adverse health effects: phase 1 of a populationbased, cross-sectional study in Germany," Occupational and Environmental Medicine, vol. 66, no. 2, pp. 118-123.

12. M. Otto and K. E. von Muhlendahl (2007). "Electromagnetic fields " (EMF): do they play a role in children's environmental health (CEH)?” International Journal of Hygiene and Environmental Health, vol. 210, no. 5, pp. 635-644.

13. M. Quamruzzaman, M. Haque, S. Haque, and Utpal Chandra Das (2020). "Electromagnetic Radiation Cell Phones Used in Dhaka City", Innovation, Systems and Technologies, Vol. 182, Springer.

14. Mobile Telecommunications and Health Research Program (MTHR), Report-2007, Pg 50http://www.mthr.org.uk/ documents/MTHR_report_2007.pdf

15. Nokia, "Looking ahead to 5G", Espoo, Finland, (2014). [Online]. Available: http: //networks.nokia.com/sites/ default/files/document/5g _white_paper_0.pdf.

16. P. Elliott, M. B. Toledano, J. Bennett et al. (2010). "Mobile phone base stations and early childhood cancers: case-control study,” British Medical Journal, vol. 340, articla c3077.

17. Prof. Girish Kumar (2010). Report on Cell Tower Radiation, December 2010, Online: GK-cell-tower-radreport-DOT-Dec2010.pdf

18. S. Reza (2019). "Environmental and Public Health Risks of Cell Phone Towers Radiation in Bangladesh", http:// dhakacourier.com.bd, Online http://www. dhakacourier.com.bd/news/Reportage/Environmental-and-PublicHealth-Risks-of-Cell-Phone-Towers-adiation-in-Bangladesh/1056.

19. Sheikh Mohammed Shariful Islam (2014). "Awareness and Self-Reported Health Hazards of Electromagnetic Waves from Mobile Phone Towers in Dhaka, Bangladesh: A Pilot Study”, Hindawi Publishing Corporation Advances in Public Health.

20. Tapasy Rabeya, Mst. Eshita Khatun, Syed Akhter Hossain (2020). "Effect of Cellular Tower Radiation towards Human Tissues at Bangladesh Context”, International Journal of Engineering and Advanced Technology, Vol.9, Issue.3, February.

21. Thae Mar Than, Su Su Yi Mon (2020). "Analysis on Electromagnetic Radiation in Mobile Base Station in Mandalay Region”, Communications, Vol.8, No.1, pp.22-27.

22. The daily Star,"HC seeks BTRC report on mobile tower radiation" (2019). https:// www.thedailystar.net/business/ telecom/cell-phone-tower-radiation-effects-hc-seeks-btrc-report-1734604

23. World Health Organization, Electromagnetic Fields and Public Health (2014). http://www.who.int/peh-emf/ publications/facts/fs296/en/. 